Available online at GSC Online Press Directory

GSC Biological and Pharmaceutical Sciences

e-ISSN: 2581-3250, CODEN (USA): GBPSC2

Journal homepage: https://www.gsconlinepress.com/journals/gscbps

(RESEARCH ARTICLE)

\title{
Utilization of bamboo water plant (Equisetum hyemale) in reducing chemical oxygen demand level of laboratory waste
}

\author{
Wulandari Fitria, Aryani Lenci and Isworo Slamet* \\ Department of Environmental Health, Faculty of Health, Dian Nuswantoro University Semarang, Indonesia.
}

Publication history: Received on 15 July 2018; revised on 08 August 2018; accepted on 20 August 2018

Article DOI: https://doi.org/10.30574/gscbps.2018.4.3.0065

\begin{abstract}
Laboratory as one of the supporting facilities of learning activities in various educational institutions, both at the primary level, intermediate and at higher education level, including in the Faculty of Health, Dian Nuswantoro University. As one of the indicators of laboratory waste pollution is the parameter of chemical oxygen demand. Utilization of bamboo water plant (Equisetum hyemale) as a remediation agent is an alternative treatment. Experiments were conducted experimentally using a completely randomized design with 75 plants, 150 plants, and 225 plants 3 and treatment ( 0 hours, 48 hours, 60 hours and 72 hours), by measuring the decrease in chemical oxygen demand concentrations. The best result was aimed at second treatment with chemical oxygen demand degraded is 430 ppm with regression equation rate $y=137 x-190$ with best degradation ability. While treatment 1 with the amount of chemical oxygen demand degraded $10 \mathrm{ppm}$ with the equation of degradation rate was $y=36 \mathrm{x}-3$, and treatment 3 with $334 \mathrm{ppm}$ degraded chemical oxygen demand with degradation rate $\mathrm{y}=112 \mathrm{x}-151$. Based on the analysis result showed Equisetum hyemale has been proven to be used as a phytoremediation agent which is quite effective in reducing the level of chemical oxygen demand, the most effective reduction of the concentration of chemical oxygen demand was found in the final treatment results using Equisetum hyemale 150 rods with the equation model $\mathrm{y}=137 \mathrm{x}-190$ with $\mathrm{R}^{2}$ $=0.85$.
\end{abstract}

Keywords: Phytoremediation; Equisetum hyemale; Chemical oxygen demand; Laboratory waste pollution

\section{Introduction}

Laboratory waste is a waste that laboratory managers must pay attention to, as it may contain ingredients that are harmful to the surrounding environment. Laboratory waste containing organic and inorganic materials needs to be reduced before being discharged into the environment through a sewage treatment plant. Waste treatment can be done chemically, physically or biologically [1].

The reduction of harmful substances into simpler and less toxic materials is often called remediation. The safest remediation of waste is to utilize native organisms since native organisms have ecologically adapted to the surrounding environment and thus have no adverse environmental impact. Remediation can be done chemically, physically and biologically. Remediation is done by utilizing biological agents called bioremediation, by utilizing microorganisms, algae, and plants. Bamboo water plants of species Equisetum hyemale is a type of aquatic plant that can be used as a remediation agent. Bamboo water plants Equisetum hyemale can reduce the heavy metal content of $\mathrm{Pb}$ and $\mathrm{Cr}$ in wastewater by $\mathrm{Pb} 82.2 \%$ and $\mathrm{Cr} 61.2 \%$ [2]. Chemical oxygen demand is one of the standard indicators of water pollution that shows the total amount of oxygen required to oxidize organic matter chemically by water activity [3].

\footnotetext{
${ }^{*}$ Corresponding author

E-mail address: slamet.isworo@dsn.dinus.ac.id
}

Copyright (C) 2018 Author(s) retain the copyright of this article. This article is published under the terms of the Creative Commons Attribution Liscense 4.0. 
In some species of Equisetum, the mature sporophyte phase forms hollow stems that have two different types. One of them is short, not branched, without chlorophyll, and produces spores as a generative tool. Others are sterile stems (also called vegetative tools), are green, and continue to grow throughout the season. This stem also acts as a photosynthetic organ replacing leaves. Structurally anatomy has a permanent network of stems consisting of the epidermis, cortex, and vascular bundles, which are thin cylindrical surrounding the central cavity. Bamboo water plant (Equisetum hyemale) has a high silicate content on the stem, this plant is able to reduce various types of pollutants [2, $4]$.

The waste remediation capacity with chemical oxygen demand content needs to be developed especially in the waste produced by the laboratory. This is because most Laboratory Activities are mostly conducted around urban settlements, so waste processing plants are needed in narrow and limited areas. Therefore the application of phytoremediation is the right step in waste management Laboratory [4]. This study aims to determine the ability of bamboo water plants in lowering levels of chemical oxygen demand contained in waste laboratory of Health Faculty - University Dian Nuswantoro, Semarang, Indonesia.

\section{Material and methods}

\subsection{Material}

The material used in the study is leachate, bamboo water plant (Equisetum hyemale) as a test plant, $\mathrm{K}_{2} \mathrm{Cr}_{2} \mathrm{O}_{7}(\mathrm{Potassium}$ Dichromate) Solution Merck's, $\mathrm{HgSO}_{4}$ (Mercury Sulfate) Solution Merck, $0.025 \mathrm{Na}_{2} \mathrm{~S}_{2} \mathrm{O}_{3}$ Solution (Sodium Tiosulfate) Merck, Aquadest (Kimia Farma, Indonesia). The tools used in this study are digital pH Meter Accurate Multi-purpose Hanna Instruments, HANNA HI 93510N and Portable Thermistor Thermometer waterproof, Memmert Oven Laboratorium UN 30 - 32 Liter (Germany).

\subsection{Preparation of plants for phytoremediation}

Acclimatization bamboo water plant (Equisetum hyemale), is done by preparing an aerator tub, bamboo water plant (Equisetum hyemale), soil as planting medium, and coral. The filling of planting medium on aerator is soil for soil (planting medium). The height of the stone layer $7-10 \mathrm{~cm}$, as the holder of bamboo water plant (Equisetum hyemale), the volume of soil used as much as $7 \mathrm{~L}$. Selection of bamboo water plants (Equisetum hyemale) used has an average height of $70 \mathrm{~cm}$ with an average diameter of $0.5 \mathrm{~mm}$, this plant is planted in a prepared aerator tub then filled with 150 L of laboratory liquid waste, faculty of Health - Dian Nuswantoro University [5]. Preparation of laboratory wastewater is the tested wastewater comes from the end result of the health laboratory treatment. The wastewater is then fed into an aerator tub with a volume of 150 liters and then tested the decrease of its chemical oxygen demand concentration with method Indonesian National Standard [6-8]

\subsection{Data analysis}

Randomized block design method was adopted to see the effect of the variables studied. The data obtained is then analyzed using regression analysis.

\section{Results and discussion}

Bamboo water plant (Equisetum hyemale) which is used in research is included in the calcification of Equisetum species, genus Equisetum, family Equisetaceae, ordo Equisetales, class Equisetopsida and division of Pteridophyta [6] . The image below shows bamboo water plant (Equisetum hyemale) used in the study: 


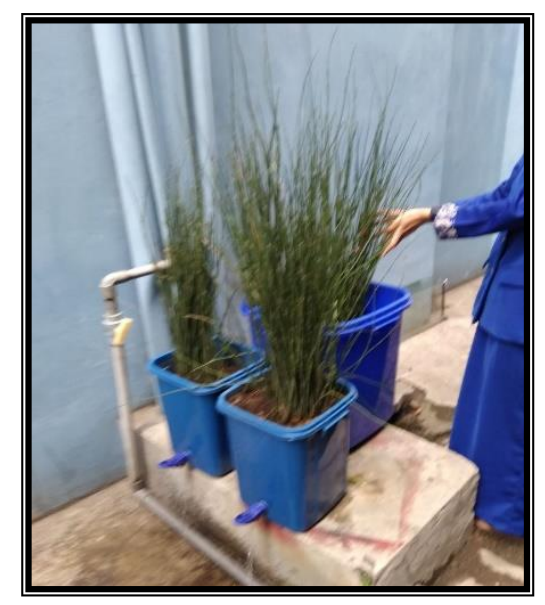

Figure 1 Bamboo water plants (Equisetum hyemale)

\subsection{Laboratory sample waste test}

Test Characteristics of laboratory waste was conducted to determine the initial concentration of the parameters studied [6]. The results of the analysis of laboratory waste characteristics can be seen in the table below, as follows

Table 1 Characteristics of laboratory liquid waste

\begin{tabular}{llll}
\hline No & Parameter & Unit & Test results \\
\hline 1 & COD & $\mathrm{mg} / \mathrm{L}$ & 652 \\
2 & $\mathrm{pH}$ & - & 4 \\
3 & Suhu & ${ }^{\circ} \mathrm{C}$ & 25 \\
\hline \multicolumn{4}{r}{${ }^{*}$ Source: primary data, 2018 }
\end{tabular}

Tabel 2 Measurement of chemical oxygen demand residual result of degradation of bamboo water plant (Equisetum hyemale)

\begin{tabular}{lllll}
\hline Treatments & \multicolumn{4}{c}{ Concentration $(\mathrm{ppm})$} \\
& 0 hour & 48 hours & 60 hours & 72 hours \\
\hline Treatment 1 & 652 & 648 & 642 & 642 \\
Treatment 2 & 652 & 602 & 522 & 222 \\
Treatment 3 & 652 & 620 & 498 & 318 \\
\hline
\end{tabular}

The result of the analysis by using linear regression is shown in the figure 2 and 3 . Based on figure 1 shows that chemical oxygen demand content after treatment using the variation of an amount of bamboo water plant (Equisetum hyemale) and day variation it can be seen that optimal result obtained from an amount of bamboo water plant (Equisetum hyemale) 150 stems. 


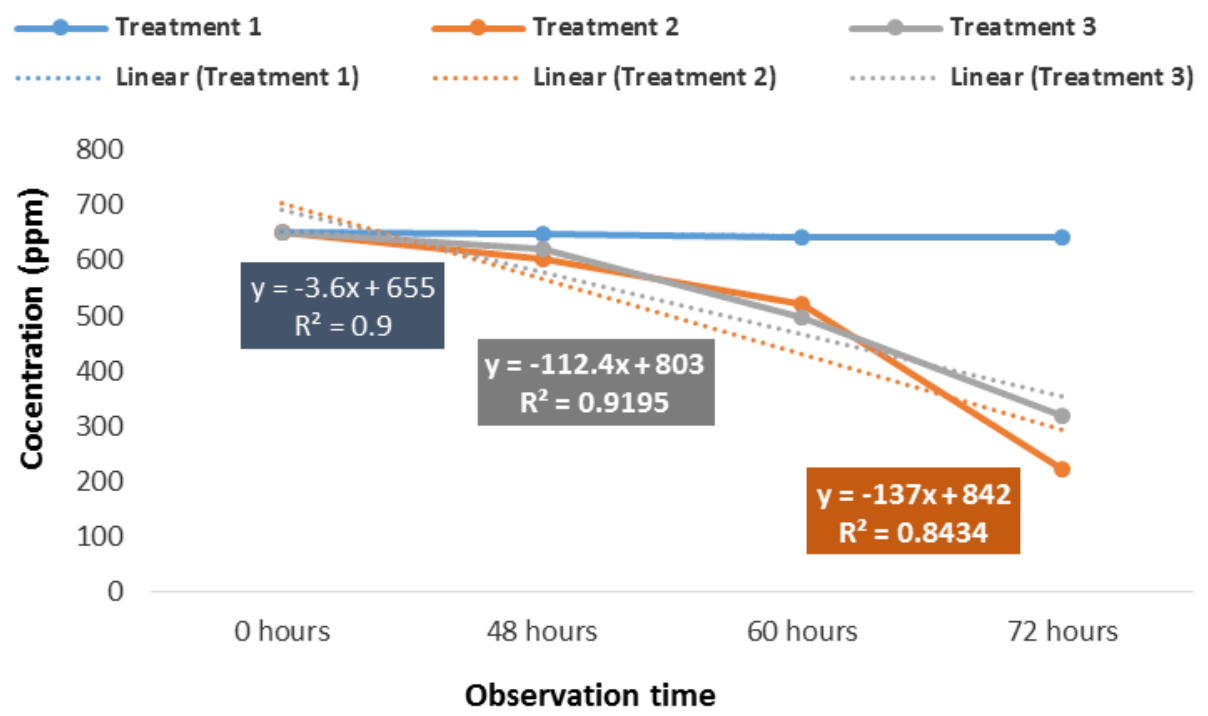

Figure 2 The level of chemical oxygen demand left over from the laboratory waste is degraded

From the results of the regression equation, it can be seen that the results of rate and model decrease in chemical oxygen demand content, as follows: treatment 1 , regression modeling $y=-3.6 \mathrm{x}+655$ with value $\mathrm{r}^{2}=0.9$, treatment 2 with regression modeling $y=-137+842$ with value $r^{2}=0.85$, treatment 3 , regression modeling $y=-112 x+803$ with value $r^{2}=0.91$. In the equation it can be shown that the best degradation rate in treatment 2 has the value $x=(-137)$, whereas the treatment 1 has the value $\mathrm{x}=(-112)$ and the $3^{\text {rd }}$ has the value $=(-3.6)$ while the negative value at the equation shows the reduction or degradation of chemical oxygen demand in the study (figure 2). This proves that bamboo water plants (Equisetum hyemale) including plant species that can be used as a phytoremediation agent (7-9).

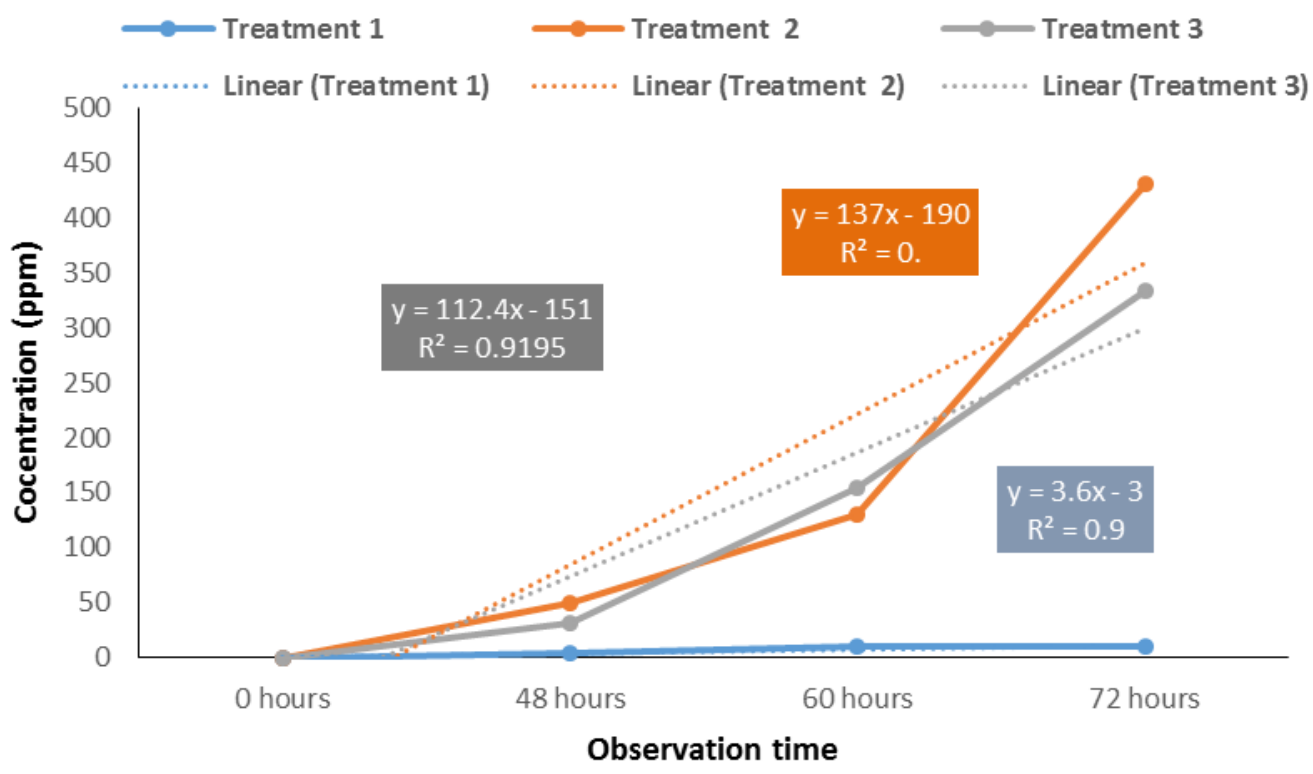

Figure 3 The degradation measurement of chemical oxygen demand concentration

The amount of chemical oxygen demand concentration that is degraded is given in figure 3 . The best result was aimed at second treatment with chemical oxygen demand degraded is $430 \mathrm{ppm}$ with regression equation rate $\mathrm{y}=137 \mathrm{x}-190$ with best degradation ability. While treatment 1 with the amount of chemical oxygen demand degraded $10 \mathrm{ppm}$ with 
the equation of degradation rate was $y=36 \mathrm{x}-3$, and treatment 3 with 334 ppm degraded chemical oxygen demand with degradation rate $y=112 x-151$ (figure 3 ).

Phytoremediation is the utilization of plants in the process of reduction and decontamination of environmental pollution either ex-situ or in-situ or reduction efforts of complex compounds with toxic to simpler compounds that are not toxic. Bamboo water plant (Equisetum hyemale) has $21 \%$ in the bath system (Lead and chromium removal from leachate using Equisetum hyemale [2].

Based on the effectiveness analysis on bamboo water plant remediation tested on laboratory waste of $150 \mathrm{~mL}$ with initial concentration of chemical oxygen demand $=652 \mathrm{ppm}$ on all treatments, showing that treatment 2 with the number of bamboo water as many as 150 plants show the best degradation ability compared with the amount of bamboo water plant 75 plants and 225 plants.

\section{Conclusion}

Bamboo water plant (Equisetum hyemale) has been proven to be used as a phytoremediation agent that is quite effective in degrading chemical oxygen demand level. The most effective decrease of chemical oxygen demand concentration was found in the final treatment result by using 150 stems of bamboo water plant (Equisetum hyemale), validation based on regression test $\mathrm{y}=-137+842$ with value $\mathrm{R}^{2}=0.85$.

\section{Compliance with ethical standards}

\section{Acknowledgments}

The authors is very grateful to the many thank's to Mrs. Lice Sabata as an assistant researcher at Environmental Health Laboratory of Dian Nuswantoro University, Semarang, Central Java, Indonesia.

\section{Disclosure of conflict of interest}

All authors declare that they have no conflict of interest.

\section{References}

[1] National Research Council. (2011). Prudent practices in the laboratory: handling and management of chemical hazards, updated version. National Academies Press.

[2] Kurniati E, Imai T, Higuchi T and Sekine M. (2014). Lead and chromium removal from leachate using horsetail (Equisetum hyemale). Journal of Degraded and Mining Lands Management, 1(2), 93-96.

[3] Saha P, Shinde 0 and Sarkar S. (2017). Phytoremediation of industrial mines wastewater using water hyacinth. International journal of phytoremediation, 19(1), 87-96.

[4] Valipour A, Raman VK and Ghole VS. (2011). Phytoremediation of domestic wastewater using Eichhornia crassipes. Journal of Environmental Science and Engineering, 53(2), 183-190.

[5] Chirakkara RA and Reddy KR. (2015). Plant species identification for phytoremediation of mixed contaminated soils. Journal of Hazardous, Toxic, and Radioactive Waste, 19(4), 04015004.

[6] The National Standardization Agency of Indonesia. (2004). Water and wastewater part 3: how to test the total suspended solid, TSS in gravimetry. http://sni.bsn.go.id/product/detail/6894.2014

[7] Truu J, Truu M, Espenberg M, Nõlvak H and Juhanson J. (2015). Phytoremediation and plant-assisted bioremediation in soil and treatment wetlands: a review. Open Biotechnol J, 9, 85-92.

[8] Environmental Protection Agency. (2011). Land remediation and pollution control division national risk management research laboratory office of research and development US. Environmental Protection Agency Cincinnati, EPA/600/R-11/088.

[9] Chen D, Fries M and Lyon JM. (2003). A statistical method of detecting bioremediation. Journal of Data Science, 1(1), 27-41. 


\section{How to cite this article}

Wulandari F, Aryani L and Isworo S. (2018). Utilization of bamboo water plant (Equisetum hyemale) in reducing chemical oxygen demand level of laboratory waste. GSC Biological and Pharmaceutical Sciences, 4(3), 18-23. 